\title{
UAB
}

Universitat Autònoma

de Barcelona

This is the accepted version of the article:

Andrés, Lidia; Padilla, Emilio. «Driving factors of GHG emissions in the EU transport activity». Transport Policy, Vol. 61 (2018), p. 60-74. DOI 10.1016/j.tranpol.2017.10.008

This version is available at https://ddd.uab.cat/record/248146

under the terms of the (cc)BY-NC-ND license 
This is the postprint version of the article:

Andrés, L., Padilla, E. (2018) "Driving factors of GHG emissions in the EU transport activity", Transport Policy, Vol. 61, pp. 60-74.

\section{DRIVING FACTORS OF GHG EMISSIONS IN THE EU TRANSPORT ACTIVITY}

\section{ABSTRACT}

This research analyzes the importance of population, economic activity, transport volume and structural characteristics of transport activity-in terms of transport energy intensity, of transport modes' share and of energy sources' mix-as driving factors of greenhouse gas emissions in transport activity in the EU-28 during the period 1990-2014. The analysis is based on the STIRPAT model, which is broadened to investigate in depth the impact on transport emissions of changes in the transport activity and in the whole economy. Using panel data econometric techniques, the significance of each factor and the impact of its change on emissions are identified. A better knowledge of the key driving forces is crucial for implementing policies focused on successfully reducing emissions in transport activity. The results allow a preliminary assessment of the potential effectiveness of the 2011 Transport White Paper measures aimed at cutting transport emissions.

Keywords: Greenhouse gas emissions; STIRPAT model; transport activity. 


\section{INTRODUCTION}

Greenhouse gas emissions decreased by $22.4 \%$ in the EU-28 between 1990 and 2014. All the source sectors contributed to this reduction with one exception, the transport sector. This sector showed completely different behavior, as its emissions increased by $13.3 \%$ during the period, from $784,507.0$ to $889,065.5$ thousand tonnes of $\mathrm{CO}_{2}$ equivalent (Eurostat, 2016) ${ }^{1}$. Consequently, the contribution of the transport sector has increased considerably since 1990, amounting to $20.8 \%$ of the overall greenhouse gas emissions in 2014 . The transport sector is currently the second most important source of emissions in the EU-28 after the energy sector.

The upward trend in emissions in the EU-28 transport sector is related to a $24.2 \%$ rise in its energy consumption over the period, reaching a total of 352,936.3 thousand tonnes of oil equivalent in 2014 , which amounted to $33.2 \%$ of the total final energy consumption. Between 1990 and 2007, in a scenario of high economic growth, the energy consumption in the EU-28 transport sector increased by $34.8 \%$ and its emissions by $25.9 \%$, whereas, between 2007 and 2014, a period of economic downturn and lower economic growth, the energy consumption of the transport sector decreased by $7.9 \%$ and its emissions by $10.0 \%$. These figures show the difficulty of mitigating greenhouse gas emissions in the transport sector, as they are the result of the level of energy consumption and the mix of energy sources used in transportation (see Table 1).

Table 1. Energy consumption in the EU-28 transport sector, total activity and classification by energy sources (thousand TOE): 1990-2014

\begin{tabular}{|c|c|c|c|c|c|}
\hline & \multicolumn{3}{|c|}{ Energy consumption } & \multicolumn{2}{|c|}{ Share } \\
\hline & 1990 & 2014 & \begin{tabular}{|c|}
$\begin{array}{c}\text { Total change } \\
(\%)\end{array}$ \\
\end{tabular} & 1990 & 2014 \\
\hline Total activity & $284,171.2$ & $352,936.4$ & $24.2 \%$ & $100.0 \%$ & $100.0 \%$ \\
\hline \multicolumn{6}{|c|}{ Sources of energy } \\
\hline Solid fuels & 213.5 & 8.6 & $-96.0 \%$ & $0.1 \%$ & $0.0 \%$ \\
\hline Petroleum products & $278,144.5$ & $330,493.1$ & $18.8 \%$ & $97.9 \%$ & $93.6 \%$ \\
\hline Gas & 338.7 & $2,955.7$ & $772.7 \%$ & $0.1 \%$ & $0.8 \%$ \\
\hline Renewable energies & 18.8 & $14,141.3$ & $75119.7 \%$ & $0.0 \%$ & $4.0 \%$ \\
\hline Electrical energy & $5,455.7$ & $5,337.7$ & $-2.2 \%$ & $1.9 \%$ & $1.5 \%$ \\
\hline
\end{tabular}

Source: Prepared by the authors with data from Eurostat (2016).

\footnotetext{
${ }^{1}$ The seven greenhouse gases considered by Eurostat data are carbon dioxide $\left(\mathrm{CO}_{2}\right)$, methane $\left(\mathrm{CH}_{4}\right)$, nitrous oxide $\left(\mathrm{N}_{2} \mathrm{O}\right)$, hydrofluorocarbons ( $\left.\mathrm{HFCS}\right)$, perfluorocarbons (PFCs), sulphur hexafluoride $\left(\mathrm{SF}_{6}\right)$ and nitrogen trifluoride $\left(\mathrm{NF}_{3}\right)$. The relevant greenhouse gases in the case of transport are $\mathrm{CO}_{2}, \mathrm{CH}_{4}$ and $\mathrm{HFCs}$.
} 
An in-depth study of the trend of greenhouse gas emissions in the EU transport activity in the last decades is necessary to assess the mitigation policies. This paper focuses on analyzing the driving factors of greenhouse gas emissions in the EU transport activity over the period 1990-2014 and on quantifying the impact of a change in any of them on such emissions using a new, extended version of the STIRPAT model. Moreover, panel data econometrics is employed to quantify the impact of the different factors. This paper, in a novel way, extends the application of the STIRPAT model to the analysis of greenhouse gas emissions in transport activity by accounting for the structural characteristics of the sector. In particular, our model includes population, economic activity, transport volume and structural characteristics-taking into account the energy intensity of the activity, the share of each mode of transport in the total activity and the share of each source of energy in the total transport energy consumption. The objective is to highlight that the effect of the activity on its emissions relies not only on the volume of transport but also on its characteristics, i.e., energy intensity, modal structure and energy source mix. As pointed out by Grazi and van den Bergh (2008), the results of the environmental policies aimed at reducing emissions in the transport sector depend on their effects on the modal split, energy efficiency, fuel type used and transport volume (passenger-kilometers or tonne-kilometers). Therefore, both the volume and the structural characteristics of the transport sector are important in explaining the change in its emissions and in designing more accurate policies. Additionally, it is relevant to consider whether there are any significant differences between regions. A further contribution of this paper is that it performs the analysis for the EU as a whole as well as differentiating by regions (western EU and eastern EU), considering their differentiated economic structures and levels of development. Finally, this paper differs from previous research, as it focuses the analysis on the greenhouse gas emissions of the transport sector instead of only the $\mathrm{CO}_{2}$ emissions. Although $\mathrm{CO}_{2}$ is the most important greenhouse gas, other greenhouse gases, $\mathrm{CH}_{4}$ and $\mathrm{N}_{2} \mathrm{O}$, are also emitted during fuel combustion ${ }^{2}$. In addition, transport activities also emit HFC gases resulting from vehicle air conditioning and refrigerated transport. It is, therefore, necessary to take into account all the greenhouses gases emitted by the activity in order to analyze the overall impact of the activity in global warming. In addition, this would eventually avoid erroneous interpretations in the cases that $\mathrm{CO}_{2}$ emissions declined at the same time that the emissions of the other three gases increased.

The main purpose of the analysis is to inform the design of environmental policies focused on mitigating environmental impacts, besides promoting efficient energy use and energy

\footnotetext{
${ }^{2}$ According to IPCC (Kahn Ribeiro et al., 2007), $\mathrm{CO}_{2}$ emissions account for around $96 \%, \mathrm{CH}_{4}$ emissions account for $0.1 \%-0.3 \%$ of total transport emissions, whereas $\mathrm{N}_{2} \mathrm{O}$ emissions account for $2.0 \%-2.8 \%$ (based on US, Japan and EU data only).
} 
savings in the transport sector. Using the results of this analysis, our research will also specifically contribute to assessing the potential effectiveness of the environmental strategies proposed in the 2011 Transport White Paper (European Commission, 2011), the aims of which include a 60\% reduction in the transport sector emissions by 2050 in relation to 1990 .

The rest of the paper is structured as follows. Section 2 provides a review of the literature. Section 3 describes the data and the methodologies employed. Section 4 presents the results and the discussion. Section 5 summarizes and concludes the paper.

\section{LITERATURE REVIEW ON THE DETERMINANTS OF TRANSPORT ACTIVITY EMISSIONS}

The role of the transport activity in greenhouse gas emissions has been studied broadly. Part of this literature is based on the IPAT identity (Ehlrich and Holdren, 1971, 1972), which is widely used as a basis for analyzing the impact of economic activity on the environment. Founded on ecological principles (York et al., 2003), it states that the environmental impact $(\mathrm{I})$ is the product of population $(\mathrm{P})$, affluence $(\mathrm{A})$ and technology $(\mathrm{T})$.

In particular, most of the investigations that study the driving factors of transport emissions are based on the IPAT identity or, alternatively, on the Kaya identity (Kaya, 1989) or the ASIF methodology (IEA, 1997), which are expanded versions of the IPAT identity. These studies use index decomposition analysis to obtain detailed information on the importance of the different driving factors explaining changes in environmental pressure over time. In this line of research, there are works focused on studying the driving factors of the transport sector emissions as a whole. For example, the investigations reported by Mazzarino (2000), Timilsina and Shrestha (2009), Guo et al. (2014) and Fan and Lei (2016), based on the IPAT identity, find that population, economic activity and transport energy intensity are the main driving forces of transport emissions ${ }^{3}$. Likewise, there are works addressing the specific driving factors of the emissions of passenger and freight transport activities. Examples of these are the investigations conducted by Scholl et al. (1996), Lakshmanan and Han (1997), Steenhof et al. (2006) and M'raihi et al. (2015). These studies are mostly based on the ASIF equation and find that the transport volume, modal share, transport energy intensity and energy $\mathrm{mix}^{4}$ are the main driving factors of emissions in these activities. Other studies investigate the driving factors of the emissions of a specific mode of transport, for instance those by Andreoni and Galmarini (2012) and Sobrino and Monzon (2014). There are even

\footnotetext{
${ }^{3}$ The investigation of Mazzarino (2000) does not identify population as a main driving factor.

${ }^{4}$ The study by Lakshmanan and Han (1997) does not include the energy mix in the analysis. As regards M'raihi et al. (2015), they point out to economic growth as the main driving factor of transport emissions.
} 
very concrete studies, such as the work by Kwon (2005) and Papagiannaki and Diakoulaki (2015), focused on finding the driving factors of the cars' emissions. These last investigations are based on the IPAT or Kaya identities and find that the main driving factors are economic activity and/or transport volume and transport energy intensity. However, all these studies, which, in essence, are based on the IPAT identity, present the same two limitations. First, it is an accounting equation and does not allow hypothesis testing, and, second, it assumes that the functional relationship between factors is proportional (York et al., 2003).

A different line of research, also based on the IPAT identity, is developed by Dietz and Rosa (1994, 1997). They propose an alternative model, the STIRPAT model (the Stochastic Impact by Regression on Population, Affluence and Technology model), which is a reformulation of the IPAT identity into a stochastic model that overcomes its limitations, as it allows estimation and hypothesis testing using econometric techniques. Various recent investigations employ the STIRPAT model to analyze the environmental impact of transport activity: Zhang and Nian (2013) and Xu and Lin $(2015,2016)$ are examples (Table 2). 
Table 2. Literature on the driving factors of transport emissions based on the IPAT identity INDEX DECOMPOSITION ANALYSIS OF THE IPAT IDENTITITY OR OF ITS EXPANDED
VERSIONS, THE KAYA IDENTITY AND THE ASIF EQUATION

\begin{tabular}{|c|c|c|c|c|}
\hline $\begin{array}{l}\text { AUTHOR AND } \\
\text { YEAR }\end{array}$ & REGION & PERIOD & AREA & DRIVING FACTORS \\
\hline Scholl et al. (1996) & $\begin{array}{l}9 \text { OECD } \\
\text { countries }\end{array}$ & $1973-1992$ & Passenger & $\begin{array}{l}\text { Passenger activity, modal structure, transport energy } \\
\text { intensity and fuel mix }\end{array}$ \\
\hline \multirow{2}{*}{$\begin{array}{l}\text { Lakshmanan and } \\
\text { Han (1997) }\end{array}$} & \multirow{2}{*}{ USA } & \multirow{2}{*}{$1970-1991$} & Passenger & $\begin{array}{l}\text { Population, people's propensity to travel, modal share, } \\
\text { mode energy intensity and interaction term }\end{array}$ \\
\hline & & & Freight & $\begin{array}{l}\text { GDP, transport intensity, modal share, mode energy } \\
\text { intensity and interaction term }\end{array}$ \\
\hline Mazzarino (2000) & Italy & $1980-1995$ & Transport & $\begin{array}{l}\text { Population, economic activity, freight transport intensity, } \\
\text { mode mix of freight transport, gross energy intensity of } \\
\text { freight transport and energy structure }\end{array}$ \\
\hline Kwon (2005) & Great Britain & 1970-2000 & Car travel & $\begin{array}{l}\text { Population, car trip distance per person and } \mathrm{CO}_{2} \\
\text { emissions per car trip distance }\end{array}$ \\
\hline Steenhof et al. (2006) & Canada & 1990-2012 & Freight & Transport volume, mode mix, fuel mix and fuel efficiency \\
\hline $\begin{array}{l}\text { Papagiannaki and } \\
\text { Diakoulaki (2009) }\end{array}$ & $\begin{array}{l}\text { Greece and } \\
\text { Denmark }\end{array}$ & $1990-2005$ & $\begin{array}{l}\text { Passenger } \\
\text { cars }\end{array}$ & $\begin{array}{l}\text { Population, vehicles per capita, average distance } \\
\text { traveled by car and the shares of cars by engine size, } \\
\text { engine technology and fuel type }\end{array}$ \\
\hline $\begin{array}{l}\text { Timilsina and } \\
\text { Shrestha (2009) }\end{array}$ & $\begin{array}{l}\text { Asian } \\
\text { countries }\end{array}$ & 1980-2005 & Transport & $\begin{array}{l}\text { Population, per capita GDP, transport energy intensity, } \\
\text { modal shift, fuel mix and fuel emission coefficient }\end{array}$ \\
\hline $\begin{array}{l}\text { Andreoni and } \\
\text { Galmarini (2012) }\end{array}$ & Europe & 2001-2008 & $\begin{array}{l}\text { Water and } \\
\text { aviation }\end{array}$ & $\begin{array}{l}\mathrm{CO}_{2} \text { intensity, transport energy intensity, structural effect } \\
\text { and economic activity }\end{array}$ \\
\hline Guo et al. (2014) & China & 2005-2012 & Transport & $\begin{array}{l}\text { Population, economic activity, transport energy intensity } \\
\text { and energy structure }\end{array}$ \\
\hline $\begin{array}{l}\text { Sobrino and Monzon } \\
\text { (2014) }\end{array}$ & Spain & 1990-2010 & Road & $\begin{array}{l}\text { GDP, workers' income intensity, job intensity, } \\
\text { motorization rate, use intensity, transport energy intensity } \\
\text { and carbon intensity }\end{array}$ \\
\hline M'raihi et al. (2015) & Tunisia & $1990-2006$ & Freight & $\begin{array}{l}\text { Economic growth, road freight intensity, petroleum } \\
\text { intensity of road freight, petroleum share of road freight } \\
\text { and average emissions of petroleum }\end{array}$ \\
\hline Fan and Lei (2016) & Beijing & 1995-2012 & Transport & $\begin{array}{l}\text { Population, economic activity, transport intensity, output } \\
\text { value of per unit traffic turnover, transport energy } \\
\text { intensity and energy structure }\end{array}$ \\
\hline \multicolumn{5}{|c|}{ ECONOMETRIC ANALYSIS OF THE STIRPAT MODEL } \\
\hline $\begin{array}{l}\text { Zhang and Nian } \\
\text { (2013) }\end{array}$ & China & 2000-2012 & Transport & $\begin{array}{l}\text { Population, per capita GDP, transport energy intensity, } \\
\text { passenger and freight turnover, and electricity and oil } \\
\text { consumption shares }\end{array}$ \\
\hline Xu and Lin (2015) & China & 1980-2012 & Transport & $\begin{array}{l}\text { Urbanization level, per capita GDP, transport energy } \\
\text { intensity, freight turnover and private vehicle population }\end{array}$ \\
\hline Xu and Lin (2016) & China & 2000-2012 & Transport & $\begin{array}{l}\text { Urbanization level, per capita GDP, transport energy } \\
\text { intensity, freight turnover and private vehicle population }\end{array}$ \\
\hline
\end{tabular}

Source: Prepared by the authors. 
Another different line of research is the literature focused on analyzing the proper design of environmental policies aimed at reducing transport emissions. The recent investigations of Tight et al. (2005), Hickman and Banister (2007), Hull (2008), Hickman et al. (2010), Banister and Hickman (2013) and Eliasson and Proost (2015) are some examples. Other studies focused on traffic flow models and simulation models and made significant contributions to understand the impacts of different variables on emissions; some examples are the works of Yu (1998), Zhu (2013) and Tang et al. (2015, 2017).

This research provides various contributions to the previous literature on the analysis of transport emissions. First, it makes a methodological contribution, as it extends the STIRPAT model by incorporating the structural composition of transportation where, besides transport energy intensity, modal share and energy mix are taken into account. Specifically, the impact on transport emissions of a change in the modal share and in the energy mix is analyzed in detail. In particular, it is quantified the impact on emissions of the substitution of rail or waterborne or aviation for road transport, and of the substitution of electricity or renewable energies or gas for oil products. Moreover, the energy intensity of the transport sector is measured in real units, in which the energy consumption of transport activity is related to passenger and freight activity-measured in gross tonne-kilometers-instead of the gross value added of the activity. Our definition of energy intensity avoids the identification of increases (reductions) in the value added of the activity as improvements (worsening) in transport energy intensity. Moreover, if transport energy intensity is defined as transport energy consumption with respect to gross tonne-moved (both passenger and freight), then transport energy intensity ameliorations would involve less energy use per unit of activity. Second, we make an empirical contribution, as the analysis is applied to the emissions of the transport sector in the EU in the period 1990-2014 and there are no similar studies for the European context. The only exceptions are the work by Andreoni and Galmarini (2012), which, however, only analyzes two specific modes of transport (water and aviation) using decomposition analysis, and the report by the European Commission ${ }^{5}$ (2013), which is not based on the IPAT identity but on the Kuznets curve hypothesis and focuses only on road transport. Third, the outcomes are used to assess the potential effectiveness of the actions adopted in the 2011 Transport White Paper oriented towards reducing transport emissions in the EU.

\section{DATA AND METHODOLOGY}

\footnotetext{
${ }^{5}$ This report analyzes the trends and drivers of the European greenhouse gas emissions, including transport sector emissions, through cause and effect analysis.
} 


\subsection{DATA}

To perform the analysis, annual data of the EU countries are collected from different sources for the period 1990-2014. Data on greenhouse gas emissions of the transport sector (in million tonnes of $\mathrm{CO}_{2}$ equivalent), population (individuals) and, in total and disaggregated by sources, energy consumption in the transport sector (in thousand tonnes of oil equivalent) are obtained from Eurostat (2016), data on real per capita GDP (in constant 2010 US\$) are taken from the World Development Indicators (World Bank, 2016) and data on transport volume-both passenger and freight (in gross tonne-kilometers)-are from the OdysseeMure database (Enerdata, 2016).

This research takes into account the emissions of the whole transport activity but excludes international bunker emissions (international maritime transport and international aviation emissions). Although international maritime transport emissions and international aviation emissions accounted for $23.4 \%$ of total transport emissions in $2014,11.7 \%$ each, (EEA, 2017), they are excluded because the data on the transport volume for international maritime transport are not available and the data for international aviation are provided in different units (in passengers but not in gross tonne-kilometers). In addition, coal is not taken into account in the analysis among the sources of energy of the transport activity. Though coal is the most polluting source of energy, during the last decades, its contribution as a source of energy to the transport sector has been reduced dramatically, so its current share in the activity is negligible (Table 1 ).

Taking into account the above, the analysis is performed for the EU as a whole (with the exception of Cyprus, Luxembourg and Malta) as well as by regions (western EU and eastern $\left.E U^{6}\right)$.

Figure 1 shows the trajectories of the greenhouse gas emissions of the transport activity in the EU countries during the period 1990-2014. Likewise, Figure 2 reports the per capita transport emissions in the EU in 1990 and in 2014 and Figure 3 presents its growth rate during that period. The descriptive statistics of the variables used in the analysis are shown in Table 3.

\footnotetext{
${ }^{6}$ The western EU includes Austria, Belgium, Denmark, Germany, Greece, Finland, France, Ireland, Italy, the Netherlands, Portugal, Spain, Sweden and the United Kingdom. The eastern EU includes Bulgaria, Croatia, the Czech Republic, Estonia, Hungary, Latvia, Lithuania, Poland, Romania, Slovenia and Slovakia.
} 
Figure 1. Greenhouse gas emissions of transport activity in western EU region and in eastern EU region, by country: 1990-2014
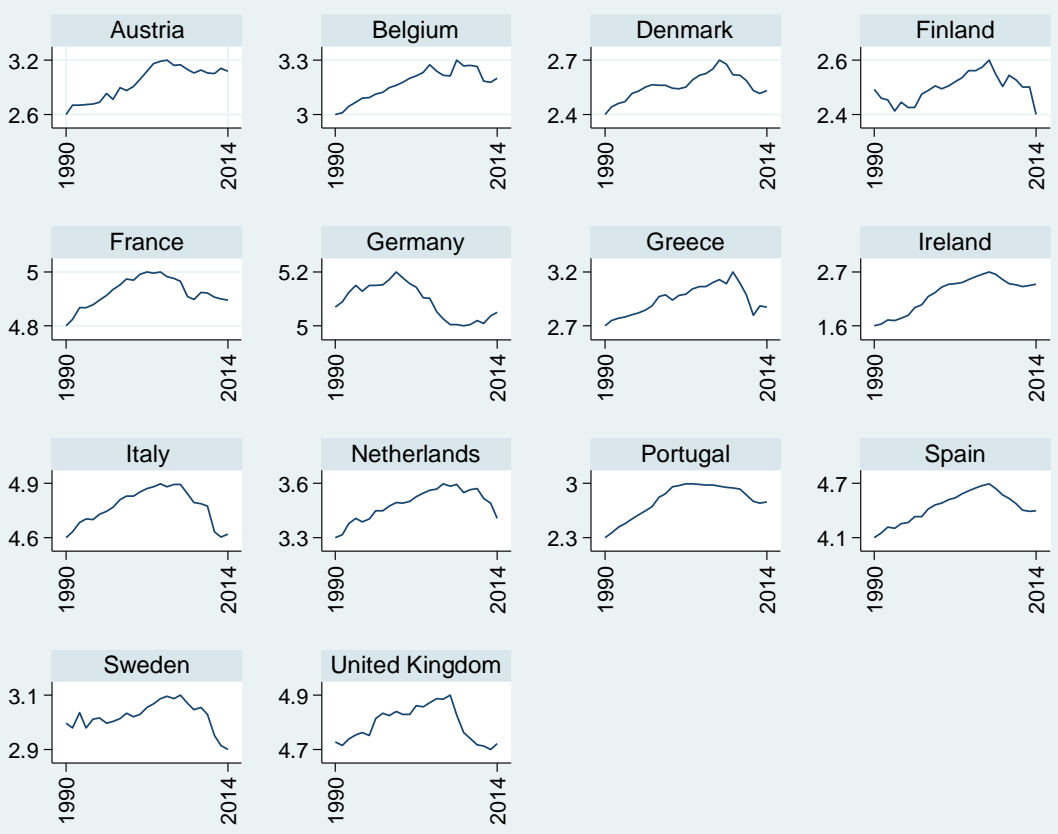

Year

Western EU countries
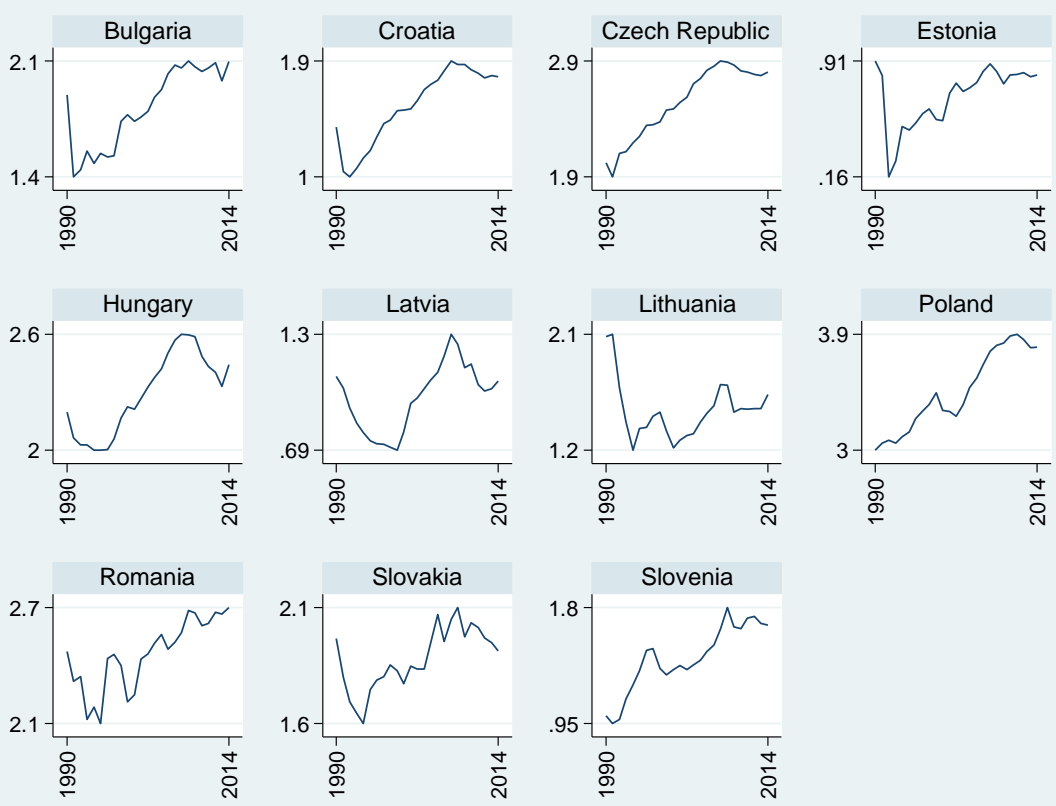

Year

Eastern EU countries

Source: Prepared by the authors with data from Eurostat (2016). 
Figure 2. Per capita greenhouse gas emissions of the EU transport activity: 1990-2014
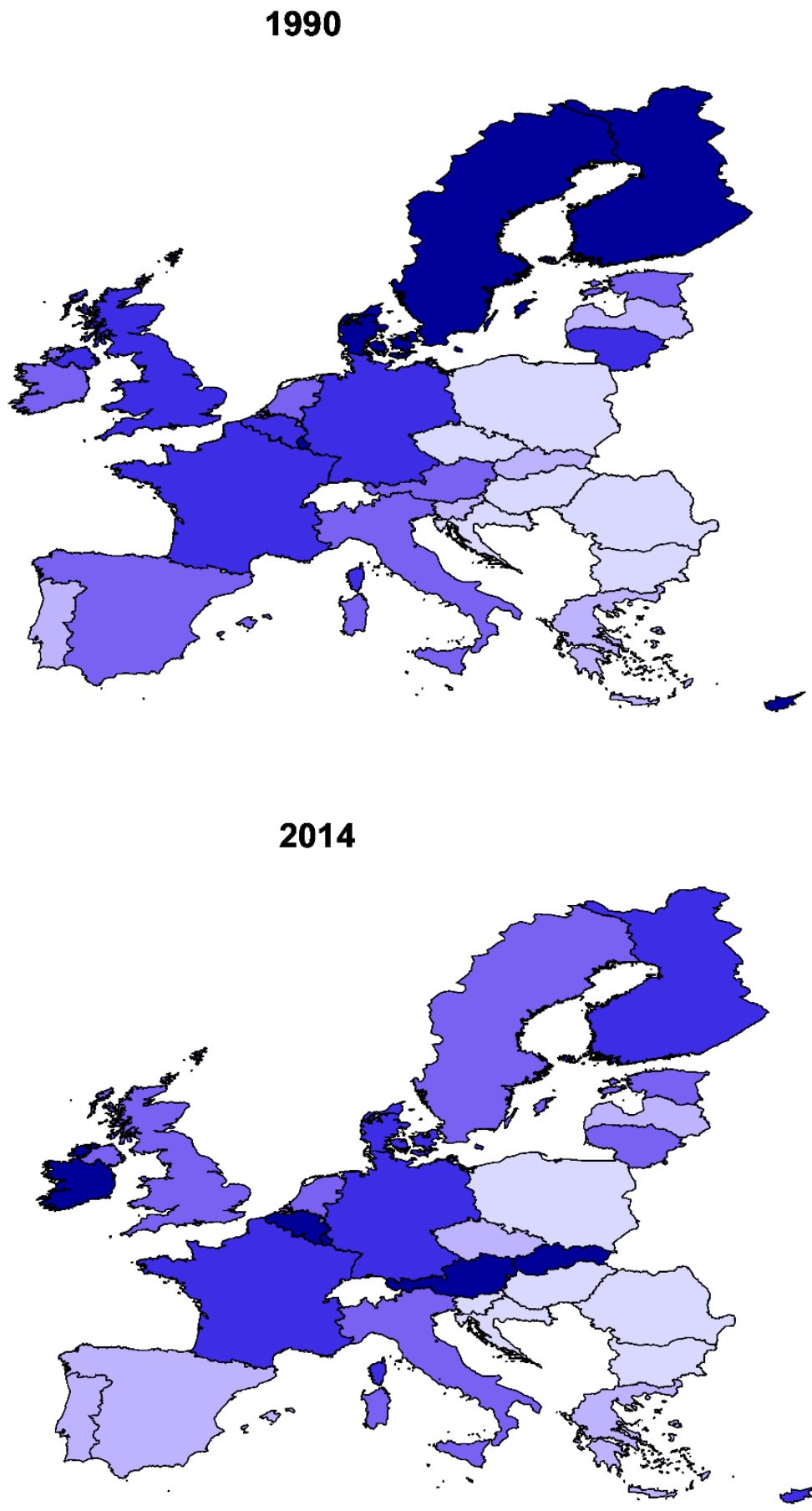

Note: The data for France are from 1991.

Source: Prepared by the authors with data from Eurostat (2016). 
Figure 3. Per capita greenhouse gas emissions' growth rate of the EU transport activity: 1990-2014

\section{$\%$ Growth rate}

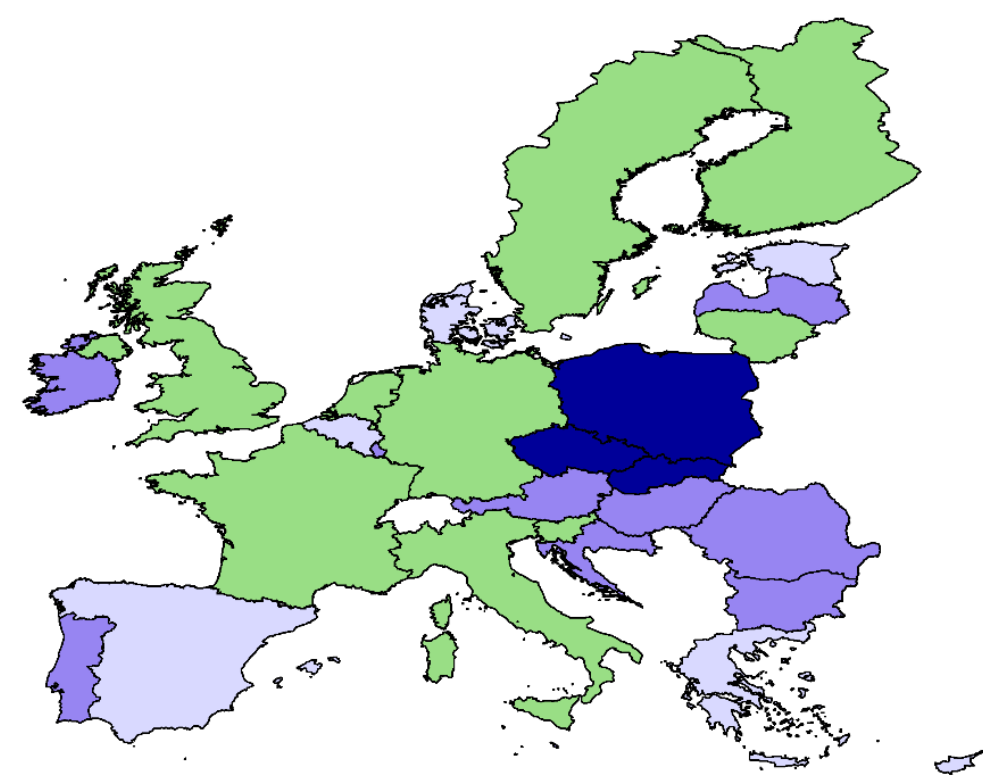

Note: The data for France are from 1991.

Source: Prepared by the authors with data from Eurostat (2016). 
Table 3. Descriptive statistics of the variables

\begin{tabular}{|l|}
\hline \multicolumn{1}{|c|}{ Variable } \\
\hline Greenhouse gas emissions \\
\hline Population \\
\hline Real per capita GDP \\
\hline Passenger activity \\
\hline Freight activity \\
\hline$\%$ Road activity \\
\hline$\%$ Rail activity \\
\hline$\%$ Aviation activity \\
\hline$\%$ Waterborne activity \\
\hline Energy consumption \\
\hline$\%$ Oil products \\
\hline$\%$ Electricity \\
\hline$\%$ Renewable energies \\
\hline$\%$ Gas \\
\hline
\end{tabular}

\begin{tabular}{|r|r|r|r|}
\hline \multicolumn{4}{|c|}{ EU countries } \\
\hline Mean & Std Dev. & \multicolumn{1}{c|}{ Min. } & \multicolumn{1}{c|}{ Max. } \\
\hline 35.747 & 47.337 & 1.168 & 186.778 \\
\hline 19500000 & 22500000 & 1320000 & 82500000 \\
\hline 26740.220 & 15375.053 & 3535.364 & 61149.530 \\
\hline 230.288 & 304.315 & 7.706 & 1118.186 \\
\hline 95.606 & 123.146 & 3.790 & 640.622 \\
\hline 0.831 & 0.099 & 0.462 & 0.975 \\
\hline 0.143 & 0.098 & 0.021 & 0.527 \\
\hline 0.007 & 0.011 & 0.000 & 0.081 \\
\hline 0.018 & 0.035 & 0.000 & 0.177 \\
\hline 13496.439 & 17926.222 & 408.800 & 67819.300 \\
\hline 0.959 & 0.042 & 0.674 & 0.999 \\
\hline 0.020 & 0.017 & 0.001 & 0.106 \\
\hline 0.011 & 0.019 & 0.000 & 0.120 \\
\hline 0.010 & 0.031 & 0.000 & 0.278 \\
\hline
\end{tabular}

\begin{tabular}{|r|r|r|r|}
\hline \multicolumn{4}{|c|}{ Western EU countries } \\
\hline \multicolumn{1}{|c|}{ Mean } & Std Dev. & \multicolumn{1}{c|}{ Min. } & \multicolumn{1}{c|}{ Max. } \\
\hline 56.674 & 54.259 & 5.135 & 186.778 \\
\hline 27200000 & 26200000 & 3510000 & 82500000 \\
\hline 37599.188 & 10025.372 & 16688.259 & 61149.530 \\
\hline 340.686 & 346.655 & 33.630 & 1118.186 \\
\hline 131.988 & 142.924 & 5.919 & 640.622 \\
\hline 0.871 & 0.063 & 0.728 & 0.975 \\
\hline 0.094 & 0.047 & 0.021 & 0.212 \\
\hline 0.009 & 0.007 & 0.000 & 0.029 \\
\hline 0.026 & 0.043 & 0.000 & 0.177 \\
\hline 21588.275 & 20413.364 & 2022.200 & 67819.300 \\
\hline 0.968 & 0.030 & 0.853 & 0.999 \\
\hline 0.016 & 0.011 & 0.001 & 0.054 \\
\hline 0.013 & 0.021 & 0.000 & 0.120 \\
\hline 0.004 & 0.007 & 0.000 & 0.034 \\
\hline
\end{tabular}

\begin{tabular}{|r|r|r|r|}
\hline \multicolumn{4}{|c|}{ Eastern EU countries } \\
\hline \multicolumn{1}{|c|}{ Mean } & Std Dev. & \multicolumn{1}{c|}{ Min. } & \multicolumn{1}{c|}{ Max. } \\
\hline 9.112 & 9.053 & 1.168 & 48.613 \\
\hline 9760000 & 1060000 & 1320000 & 38700000 \\
\hline 11353.019 & 4963.380 & 3535.364 & 25448.964 \\
\hline 61.115 & 56.720 & 7.706 & 254.412 \\
\hline 42.728 & 53.207 & 3.790 & 313.043 \\
\hline 0.770 & 0.113 & 0.462 & 0.924 \\
\hline 0.219 & 0.108 & 0.063 & 0.527 \\
\hline 0.005 & 0.014 & 0.000 & 0.081 \\
\hline 0.006 & 0.010 & 0.000 & 0.051 \\
\hline 3197.738 & 3312.903 & 408.800 & 17906.600 \\
\hline 0.947 & 0.052 & 0.674 & 0.995 \\
\hline 0.026 & 0.020 & 0.003 & 0.106 \\
\hline 0.009 & 0.015 & 0.000 & 0.062 \\
\hline 0.018 & 0.045 & 0.000 & 0.278 \\
\hline
\end{tabular}

Source: Prepared by the authors with data from Enerdata (2016), Eurostat (2016) and the World Bank (2016).

Note: Greenhouse gas emission units are in million tonnes of $\mathrm{CO}_{2}$ equivalent; population is measured as the number of people; real per capita GDP is stated in constant 2010 US\$; passenger and freight activities are measured in gross tonne-kilometers; and energy consumption is given in thousand TOE. 


\subsection{AN EXTENDED STIRPAT MODEL FOR THE ANALYSIS OF TRANSPORT ACTIVITY EMISSIONS}

The STIRPAT model formula is as follows:

$$
I=a+\beta_{1} P+\beta_{2} A+\beta_{3} T+\varepsilon
$$

where $I$ is the environmental impact, $a$ is a constant, $P$ is the population, $A$ is affluence, usually proxied by per capita activity, $T$ is technology, typically measured as the impact per unit of activity, $\varepsilon$ is the error term and $\beta_{i}$ are the estimated parameters. All the variables are taken in log form, so $\beta_{i}$ can be interpreted as "ecological elasticities" (York et al., 2013), which indicate the sensitivity of environmental impacts to a change in any driving factor.

This paper employs a new extended STIRPAT model to identify the driving factors of the emissions in transport activity, in which, besides including population and affluence, the technology factor is decomposed in a novel way to obtain more detailed results focused on the activity. In particular, technology is decomposed to take into account not only the transport energy intensity but also the activity volume of the transport sector and its structural composition in terms of modes of transport and sources of energy. The novelty of this methodology relies on, first, introducing into the model the share of all modes of transport in the total activity and the share of all sources of energy in the total transport energy consumption-so that it is stressed that the effect on emissions in the transport sector depends on both the transport volume and its composition (in terms of both activity and energy consumption) -and, second, considering an alternative unit of measurement of transport energy intensity. In the previous literature, the energy intensity of transport activity is measured as the total transport energy consumption with respect to the gross value added of the activity. ${ }^{7}$ This definition could lead to misleading results, since increases in the value added of the activity would indicate false improvements in transport energy intensity ${ }^{8}$, whereas if it is defined with respect to gross tonne-moved (both passenger and freight), then, transport energy intensity enhancements would involve less energy use per unit of transport activity. Therefore, transport energy intensity is defined as transport energy consumption divided by the sum of passenger and freight activities, both measured in gross tonnekilometers.

\footnotetext{
${ }^{7}$ With the exception of the studies focused on analyzing passenger or freight transport emissions, that is, the works of Scholl et al. (1996), Lakshmanan and Han (1997), Steenhof et al. (2006) and M'raihi (2015) who define energy intensity as energy use per passenger-kilometer (or passenger-mile) or as energy use per tonne-kilometer (or tonne-mile) depending on whether the study analyzes passenger or freight transport emissions. Another exception is the work of Sobrino and Monzon (2014), who define the energy intensity of road transport as the total energy use per total kilometers driven on the road.

${ }^{8}$ For instance, higher value added of a commodity does not imply that fewer tonne-kilometers of it are transported.
} 
After performing an analysis of the correlation ${ }^{9}$ between the variables and a study of multicollinearity ${ }^{10}$ (see Tables A3 and A4 in the Appendix), the econometric model selected takes the following form:

$$
\begin{gathered}
G H G_{i t}=\alpha_{i}+\gamma_{t}+\beta_{1} P_{i t}+\beta_{2} G D P_{i t}+\beta_{3} E I_{i t}+\beta_{4} T A_{i t}+\sum_{j=1}^{J-1} \mu_{j} M_{j i t}+\sum_{k=1}^{K-1} \Omega_{k} S_{k i t}+\varepsilon_{i t} \\
i=1, \ldots, 25 ; t=1990, \ldots, 2014
\end{gathered}
$$

where $i$ denotes the country; $t$ refers to the year; $j$ indicates the different modes of transport, road, rail, aviation and waterborne; and $k$ are the sources of energy of the activity, oil, electricity, renewable energies and gas. ${ }^{11}$ Likewise, $G H G_{i, t}$ are the total greenhouse gas emissions in the transport sector for country $i$ and year $t, P_{i, t}$ is the total population; $G D P_{i, t}$ is the real per capita GDP; $E I_{i, t}$ is the transport energy intensity, which is defined as the total transport energy consumption divided by the total transport volume (passenger and freight activities); and $T A_{i t}$ is the per capita freight activity and measures the activity volume. All the variables are taken in log form, which implies that the estimated coefficients $\beta_{i}$ denote the elasticity of greenhouse gas emissions of the transport activity with respect to each driving factor. The unobserved country-specific variables $\alpha_{i}$ collect all the fixed factors that characterize each country and are time invariant. The terms $\gamma_{t}$ refer to a time-specific constant that brings together all time-related shocks that are common to all countries. $M_{j}$ is the share of modal transport $j$ in the total transport volume, where $J=4$, given that we consider four modes of transport, with $\sum_{j=1}^{J} M_{j i t}=1, \forall i, t$. Similarly, $S_{k}$ is the share of energy source $k$ in the total energy consumption of the transport activity, where $K=4$, with $\sum_{k=1}^{K} S_{k i t}=1, \forall i, t$. One mode of transport $\left(M_{j}\right)$ and one source of energy $\left(S_{k}\right)$ are omitted to estimate the above equation to avoid multicollinearity problems. Road transport is the omitted modal transport; thus, the parameter estimates $\mu_{j}$ are semi-elasticities and they must be interpreted as the impact on transport emissions of an increase of $1 \%$ in the share on transport activity of an alternative mode of transport-rail, aviation or waterborne -at the expense of a reduction of $1 \%$ in the share of road transport, other things being equal. In the same way, the source of energy omitted is oil products, which means that parameter

\footnotetext{
${ }^{9}$ The pairwise correlation coefficients seem to show some problems of collinearity between transport energy intensity and rail share when considering the EU as a whole and between rail share and electricity share when considering the western EU. However, as we will see later, the results with respect to the three variables involved are robust.

${ }_{10}$ Transport volume was first defined as the sum of passenger and freight activities; however, an analysis of multicollinearity showed problems between transport volume and population. To solve this, transport volume was then defined as only freight activity, and the multicollinearity problems disappeared.

${ }_{11}$ As noted above, coal is not taken into account in the analysis given its negligible value. During the last decade, it has been used only in a few steam locomotives in the UK (Eurostat, 2016).
} 
estimates $\Omega_{k}$ are semi-elasticities and they must be interpreted as the impact on transport emissions originated by a $1 \%$ rise in the share of an alternative source of energy-electricity, renewable energies or gas-at the expense of a decrease of $1 \%$ in the share of oil products, all other things being equal. Finally, $\varepsilon_{i t}$ are the error terms.

Table 4. Units and definitions of the data used in the model

\begin{tabular}{|l|l|l|}
\hline Variable & $\begin{array}{l}\text { Units of } \\
\text { measurement }\end{array}$ & Definition \\
\hline$G H G$ & $\begin{array}{l}\text { Million tonnes of } \\
\mathrm{CO}_{2} \text { equivalent }\end{array}$ & Total greenhouse gas emissions of the transport sector \\
\hline$P$ & Number of people & Population \\
\hline$G D P$ & Constant 2010 US\$ & Real per capita gross domestic product \\
\hline$E I$ & $\begin{array}{l}\text { Thousand TOE } \\
\text { per gross tonne- } \\
\text { kilometer }\end{array}$ & $\begin{array}{l}\text { Transport energy intensity defined as the total energy } \\
\text { consumption of transport activity divided by the total } \\
\text { transport volume (passenger and freight) }\end{array}$ \\
\hline$T A$ & $\begin{array}{l}\text { Gross tonne- } \\
\text { kilometers }\end{array}$ & Transport volume measured as the per capita freight activity \\
\hline$M_{j}$ & Percentage & Ratio of mode of transport $j$ in the total transport volume \\
\hline$S_{k}$ & Percentage & $\begin{array}{l}\text { Ratio of source of energy } k \text { in the total energy consumption } \\
\text { of transport activity }\end{array}$ \\
\hline
\end{tabular}

Source: Prepared by the authors

\subsection{ESTIMATION METHODS}

There are two basic econometric models that can be used in panel data analysis: the fixedeffects model (FE) and the random-effects model (RE). Given the unobserved countryspecific heterogeneity of the panel data, it is appropriate to control all the time-invariant characteristics of each country not considered in the model. By definition, these timeinvariant characteristics do not have any influence on the evolution of the dependent variable, as they are constant for each country. In econometric terms the $\alpha_{i}$ terms are treated as regression parameters. The FE model, unlike the RE model, provides results that are conditional on the country effects of the sample data used, so they cannot be extrapolated to other samples of data (Hsiao, 1986; Stern, 2004). That is, the FE model is suitable if the analysis is restricted to a particular group of countries, while the RE model is appropriate when applied to a random set of countries. After carrying out the test of fixed vs. random effects of overidentifying restrictions implemented by Schaffer and Stillman (2010), which unlike Hausman test allows for heteroskedasticity and within-group correlation, the FE model is chosen to estimate Equation 2 both for the EU as a whole and for the western EU region. In relation to the eastern region, although the previous test pointed out that the pooled OLS 
model was better than the RE model ${ }^{12}$, the $F$ test rejected equal fixed effects across countries, which indicated that the best model is the FE model (Table 5). Therefore, the FE model is also chosen to estimate Equation 2 in the eastern EU region.

Table 5. Fixed versus Random Effects

\begin{tabular}{|l|c|c|c|c|c|c|}
\hline & \multicolumn{2}{|c|}{ EU } & \multicolumn{2}{c|}{ Western EU } & \multicolumn{2}{c|}{ Eastern EU } \\
\hline & Test stat. & p-value & Test stat. & p-value & Test stat. & p-value \\
\hline Wald stat. & 21.191 & 0.0198 & 213.535 & 0.0000 & --- & --- \\
\hline F stat. & --- & --- & --- & --- & 17.20 & 0.0000 \\
\hline
\end{tabular}

Source: Prepared by the authors with data from Enerdata (2016), Eurostat (2016) and the World Bank (2016).

After estimating our FE model, other tests are carried out to determine whether any of the classic econometric assumptions are violated, that is, if there are problems of autocorrelation, heteroskedasticity or cross-sectional dependence, in which case the estimated parameters of FE would be biased and, instead, the suitable econometric model would be the panel corrected standard error model (PCSE) or the feasible generalized least squares model (FGLS). Both the PCSE and the FGLS analyze panel data with problems of heteroskedasticity and/or contemporaneous correlation, with or without autocorrelation, although the first model is more appropriate when $N>T$ and the second otherwise (Hoechle, 2007).

The tests used to identify the problems mentioned above are: i) the Wooldridge test for serial correlation, which is used to test for autocorrelation, that is, whether or not the errors of each country are temporally correlated (first-order autocorrelation), and the null hypothesis of this test is no first-order autocorrelation; ii) the modified Wald test for heteroskedasticity, which is used to test for heteroskedasticity, that is, whether or not the variances of the errors of each country are constant, the null hypothesis of this test being no heteroskedasticity; iii) the Pesaran CD test, which is used to test for contemporaneous correlation, that is, whether or not the residuals are correlated across countries, the null hypothesis of this test being sectional independence.

All the variables of our model are detrended, taking them as deviations from period means, which is a standard procedure in the literature (Marrero, 2010). Consequently, the timespecific term $\gamma_{t}$ is omitted from the model.

\footnotetext{
${ }^{12}$ The estimate of sigma_u was equal to zero, therefore, all the country-specific intercepts were the same.
} 
Likewise, as taking into account the behavior of the series shown in Figure 1, two facts were taken into account in the estimation of Equation 2. First, the greenhouse gas emissions of the transport activity in the western EU region began to decrease in 2008 as a result of the financial and economic crisis. Second, the greenhouse gas emissions of the transport activity in the eastern EU region showed a sharp plunge in the early nineties as a consequence of the economic crisis endured by the region during those years. As transport emissions seemed to show different patterns during the period analyzed, we tested the significance of these patterns using two different strategies in the estimation of Equation 2: first, we included time dummies for each year of the period analyzed; second, we included time trends for the different years of the period analyzed. However, as the results were robust and not affected by the introduction of the time dummies or the time trends, we did not include them in the final model.

\section{RESULTS AND DISCUSSION}

The Wooldridge test, the modified Wald test and the Pesaran CD test, when respectively applied to the FE model, point to the existence of heteroskedasticity and serial correlation but not contemporaneous correlation. These results hold when analyzing the EU both as a whole and by regions (Table 6).

Table 6. Group-wise heteroskedasticity, serial correlation and cross-sectional dependence tests

\begin{tabular}{|l|r|r|r|r|r|r|}
\hline & \multicolumn{2}{|c|}{ EU } & \multicolumn{2}{c|}{ Western EU } & \multicolumn{2}{c|}{ Eastern EU } \\
\hline & Test stat. & p-value & Test stat. & p-value & Test stat. & p-value \\
\hline F stat. & 144.287 & 0.000 & 32.780 & 0.000 & 71.550 & 0.000 \\
\hline Wald stat. & 3883.930 & 0.000 & 155.700 & 0.000 & 189.780 & 0.000 \\
\hline CD stat. & 0.330 & 0.741 & -1.064 & 1.713 & -0.462 & 1.356 \\
\hline
\end{tabular}

Source: Prepared by the authors with data from Enerdata (2016), Eurostat (2016) and the World Bank (2016)

To solve these two problems, we estimate a PCSE and an FGLS with country fixed effects when considering the EU as a whole, given that the database is $N=T$. The FE, the PCSE and the FGLS estimates of Equation 2 for the EU are reported in Table 7. When analyzing the EU regions, we also estimate a PCSE and an FGLS with country fixed effects, but, because the database is now $N<T$, the FGLS results are the most appropriate. The FE, the 
PCSE and the FGLS estimates of Equation 2 for the western EU and the eastern EU are reported in Tables 8 and 9, respectively.

\subsection{DRIVING FACTORS OF TRANSPORT EMISSIONS IN THE EU}

Table 7 shows the results for the EU as a whole. All the signs of the estimated parameters are as expected. The elasticities of emissions with respect to population, real per capita GDP, transport volume and transport energy intensity are positive and statistically significant. All these elasticities are higher than zero but below the unit, indicating that a change in any of these driving factors, all other things being equal, would mean less than a proportional change in the same sign for transport emissions.

Table 7. Estimates of driving factors of greenhouse gas emissions in the transport activity of the EU

\begin{tabular}{|c|c|c|c|c|c|c|}
\hline \multicolumn{7}{|c|}{ Dependent variable: Transport emissions } \\
\hline & \multicolumn{2}{|c|}{$\mathrm{FE}$} & \multicolumn{2}{|c|}{ PCSE } & \multicolumn{2}{|c|}{ FGLS } \\
\hline Population & $1.009^{* * *}$ & $(0.190)$ & $0.987^{* * *}$ & $(0.111)$ & $0.881^{* * *}$ & $(0.084)$ \\
\hline Real per capita GDP & $0.345^{* * *}$ & $(0.103)$ & $0.344^{* * *}$ & $(0.034)$ & $0.304^{* * *}$ & $(0.025)$ \\
\hline Transport energy intensity & $0.616^{* * *}$ & $(0.135)$ & $0.642^{* * *}$ & $(0.029)$ & $0.704^{* * *}$ & $(0.025)$ \\
\hline Transport volume & $0.345^{* * *}$ & $(0.072)$ & $0.315^{* * *}$ & $(0.021)$ & $0.317^{* * *}$ & $(0.017)$ \\
\hline Rail share & $-0.784^{* * *}$ & $(0.248)$ & $-0.563^{* * *}$ & $(0.105)$ & $-0.528^{* * *}$ & $(0.085)$ \\
\hline Aviation share & 0.521 & $(0.994)$ & 0.608 & $(0.525)$ & $1.298^{* *}$ & $(0.540)$ \\
\hline Waterborne share & -1.450 & $(0.918)$ & $-0.770^{*}$ & $(0.413)$ & $-0.959^{* * *}$ & $(0.247)$ \\
\hline Electricity share & 1.146 & $(1.858)$ & -0.329 & $(0.548)$ & $-1.149^{* *}$ & $(0.533)$ \\
\hline Renewable energies' share & $-1.328^{* * *}$ & $(0.422)$ & $-1.191^{* * *}$ & $(0.213)$ & $-1.023^{* * *}$ & $(0.136)$ \\
\hline Gas share & $-0.711^{* *}$ & $(0.315)$ & $-0.409^{*}$ & $(0.111)$ & $-0.567^{* * *}$ & $(0.198)$ \\
\hline Constant & $2.577^{* * *}$ & $(0.075)$ & $2.541^{* * *}$ & $(0.034)$ & $2.583^{* * *}$ & $(0.025)$ \\
\hline Country & \multicolumn{2}{|c|}{ Yes } & \multicolumn{2}{|c|}{ Yes } & \multicolumn{2}{|c|}{ Yes } \\
\hline Year & \multicolumn{2}{|c|}{ Yes } & \multicolumn{2}{|c|}{ Yes } & \multicolumn{2}{|c|}{ Yes } \\
\hline $\mathrm{R}^{2}$ & \multicolumn{2}{|c|}{0.873} & \multicolumn{2}{|c|}{0.994} & & \\
\hline $\mathrm{F}$ & \multicolumn{2}{|c|}{58.4} & \multirow{2}{*}{\multicolumn{2}{|c|}{538}} & \multirow{2}{*}{\multicolumn{2}{|c|}{538}} \\
\hline $\mathrm{N}$ & \multicolumn{2}{|c|}{538} & & & & \\
\hline
\end{tabular}

Clustered standard errors by country in parentheses.

${ }^{*} p<0.1,{ }^{* *} p<0.05,{ }^{* * *} p<0.01$

Note: Transport emissions, population, real per capita GDP, transport energy intensity and transport volume are taken in natural logarithms.

In particular, the elasticity of transport energy intensity indicates that a $1 \%$ decrease in energy intensity contributes to reducing transport emissions in about $0.704 \%$. However, given the parameters estimated for population, real per capita GDP and transport volume, $0.881,0.304$ and 0.317 , respectively, its positive effect is limited. The growth of population, economic activity and transport volume counteracts the positive impact of energy efficiency enhancements. In addition, it must be noticed that, when the whole impact of efficiency 
improvements is evaluated, it has to be taken into account that it may exert an impact on other variables, such as the transport volume, through the rebound effect (see Greening et al., 2000, for a survey of the rebound effect due to energy efficiency improvements). However, we focus here on the direct drivers of transport emissions and, though possible rebound effects have to be considered when analyzing the results, their computation is beyond the scope of this paper.

In relation to the parameter estimates of the modal transport share, rail and waterborne transport are the ones for which the coefficients are statistically significant, being -0.528 and -0.959 , respectively. Their negative signs indicate that a reduction in the road transport share in favor of rail or waterborne transport would lead to a decrease in activity emissions. In fact, our results point out that the substitution of rail for road is apparently more effective in reducing transport emissions than the substitution of waterborne transport for road. As regards the estimated coefficient for the aviation transport share, although positive, it is not statistically significant, at least not in all the specifications. It should be recalled that international aviation is not taken into account in this study because of a lack of equivalent data. Had we been able to add international aviation, the expected estimated parameter is very likely to have been statistically significant and would probably have indicated that an increase in the aviation transport share at the expense of road transport increases the greenhouse gas emissions of the EU transport activity.

As for the energy sources, the parameter estimates for renewable energies and gas, with coefficients of -1.023 and -0.567 , respectively, are statistically significant in all the specifications, while electricity is statistically significant in the FGLS. The negative sign of their estimated coefficients indicates that the substitution of electricity, renewable energies or gas for oil products would result in a reduction of greenhouse gas emissions in transport activity. Taking into account the fact that our analysis is not conclusive regarding electricity, the results show that the greatest effect corresponds to renewable energies, as evidenced by their higher estimated parameter. Although this outcome related to electricity is surprising, the analysis by regions could shed some light on it.

\subsection{DRIVING FACTORS OF TRANSPORT EMISSIONS IN THE EU REGIONS}

The FGLS outcomes shown in Tables 8 and 9 reveal that there are no great differences between the results of the western and eastern regions as regards the signs and significance of the estimated parameters. The outcomes of the estimations for these groups confirm those obtained for the EU as a whole, which is proof of the robustness of our results. 
Table 8. Estimates of driving factors of greenhouse gas emissions in the transport activity of the western EU

\begin{tabular}{|c|c|c|c|c|c|c|}
\hline \multicolumn{7}{|c|}{ Dependent variable: Transport emissions } \\
\hline & \multicolumn{2}{|c|}{$\mathrm{FE}$} & \multicolumn{2}{|c|}{ PCSE } & \multicolumn{2}{|c|}{ FGLS } \\
\hline Population & $0.482^{*}$ & $(0.255)$ & $0.640^{* * *}$ & $(0.133)$ & $0.819^{* * *}$ & $(0.114)$ \\
\hline Real per capita GDP & $0.565^{* * *}$ & $(0.133)$ & $0.561^{* * *}$ & $(0.044)$ & $0.399 * * *$ & $(0.039)$ \\
\hline Transport energy intensity & $0.483^{* * *}$ & $(0.115)$ & $0.598 * * *$ & $(0.036)$ & $0.634^{* * *}$ & $(0.033)$ \\
\hline Transport volume & $0.141^{* *}$ & $(0.064)$ & $0.168^{* * *}$ & $(0.020)$ & $0.216^{* * *}$ & $(0.020)$ \\
\hline Rail share & $-5.829 * * *$ & $(1.051)$ & $-3.484 * * *$ & $(0.285)$ & $-2.851^{* * *}$ & $(0.254)$ \\
\hline Aviation share & -0.405 & $(5.143)$ & -0.903 & $(1.285)$ & 1.257 & $(1.215)$ \\
\hline Waterborne share & -0.564 & $(0.681)$ & $-0.707^{* *}$ & $(0.357)$ & $-0.761^{* * *}$ & $(0.295)$ \\
\hline Electricity share & $-6.861^{* * *}$ & (1.696) & $-4.496^{* * *}$ & $(0.967)$ & $-2.646^{* * *}$ & $(0.840)$ \\
\hline Renewable energies' share & -0.835 & $(0.486)$ & $-1.168^{* * *}$ & $(0.197)$ & $-1.067^{* * *}$ & $(0.163)$ \\
\hline Gas share & -1.303 & $(1.798)$ & -0.574 & $(0.695)$ & $-1.278^{* *}$ & $(0.614)$ \\
\hline Constant & $2.614^{* * *}$ & $(0.140)$ & $2.762^{* * *}$ & $(0.040)$ & $2.764^{* * *}$ & $(0.039)$ \\
\hline Country & \multicolumn{2}{|c|}{ Yes } & \multicolumn{2}{|c|}{ Yes } & \multicolumn{2}{|c|}{ Yes } \\
\hline Year & \multicolumn{2}{|c|}{ Yes } & \multirow{2}{*}{\multicolumn{2}{|c|}{$\begin{array}{c}\text { Yes } \\
0.997\end{array}$}} & \multicolumn{2}{|c|}{ Yes } \\
\hline $\mathrm{R}^{2}$ & \multicolumn{2}{|c|}{0.928} & & & & \\
\hline $\mathrm{F}$ & \multicolumn{2}{|c|}{453.5} & \multicolumn{2}{|c|}{0.991} & \multirow{2}{*}{\multicolumn{2}{|c|}{330}} \\
\hline $\mathrm{N}$ & 3 & & \multicolumn{2}{|c|}{330} & & \\
\hline
\end{tabular}

Clustered standard errors by country in parentheses.

${ }^{*} p<0.1,{ }^{* *} p<0.05,{ }^{* * *} p<0.01$

Note: Transport emissions, population, real per capita GDP, transport energy intensity and transport volume are taken in natural logarithms.

In particular, the elasticities of greenhouse gas emissions with respect to population, real per capita GDP, transport volume and transport energy intensity are positive but below the unity and statistically significant in both regions. Regardless of the region, the effect on emissions of a change in the population or transport energy intensity is greater than that of real per capita GDP or transport volume. However, it is worth noting that, in the western region, the larger relative impact on transport emissions corresponds to a change in the population with an elasticity of $0.819 \%$, while the transport energy intensity with an elasticity of $0.814 \%$ is the driving factor with the greater relative impact on emissions in the eastern region. While energy efficiency would contribute to mitigating the emissions of the transport sector in both regions, its impact would be larger in the eastern EU region. We explain in the discussion and policy implications' section the reason for the larger significance of transport energy intensity for the eastern EU region. 
Table 9. Estimates of driving factors of greenhouse gas emissions in the transport activity of the eastern EU

\begin{tabular}{|c|c|c|c|c|c|c|}
\hline \multicolumn{7}{|c|}{ Dependent variable: Transport emissions } \\
\hline & \multicolumn{2}{|c|}{$\mathrm{FE}$} & \multicolumn{2}{|c|}{ PCSE } & \multicolumn{2}{|c|}{ FGLS } \\
\hline Population & 0.498 & $(0.302)$ & $0.603 * *$ & $(0.240)$ & $0.691 * * *$ & $(0.204)$ \\
\hline Real per capita GDP & 0.129 & $(0.115)$ & $0.115 * *$ & $(0.057)$ & $0.221 * * *$ & $(0.048)$ \\
\hline Transport energy intensity & $0.889 * * *$ & $(0.072)$ & $0.742 * * *$ & $(0.043)$ & $0.814 * * *$ & $(0.040)$ \\
\hline Transport volume & $0.544 * * *$ & $(0.062)$ & $0.498 * * *$ & $(0.037)$ & $0.469 * * *$ & $(0.034)$ \\
\hline Rail share & $-0.685 * * *$ & $(0.174)$ & $-0.622 * * *$ & $(0.126)$ & $-0.444 * * *$ & $(0.101)$ \\
\hline Aviation share & $1.172 *$ & $(0.595)$ & $1.063 *$ & $(0.590)$ & $1.324 * * *$ & $(0.477)$ \\
\hline Waterborne share & -1.501 & $(1.224)$ & 0.181 & $(0.979)$ & -0.874 & $(1.111)$ \\
\hline Electricity share & $1.945 * *$ & $(0.821)$ & 0.394 & $(0.745)$ & 0.377 & $(0.750)$ \\
\hline Renewable energies'share & $-2.358 * * *$ & $(0.732)$ & $-1.817 * * *$ & $(0.434)$ & $-1.500 * * *$ & $(0.375)$ \\
\hline Gas share & $-0.789 * * *$ & $(0.213)$ & $-0.434 * * *$ & $(0.136)$ & $-0.562 * * *$ & $(0.201)$ \\
\hline Constant & $2.409 * * *$ & $(0.140)$ & $2.558 * * *$ & $(0.070)$ & $2.715 * * *$ & $(0.060)$ \\
\hline Country & \multicolumn{2}{|c|}{ Yes } & \multicolumn{2}{|c|}{ Yes } & \multicolumn{2}{|c|}{ Yes } \\
\hline Year & \multicolumn{2}{|c|}{ Yes } & \multicolumn{2}{|c|}{ Yes } & \multicolumn{2}{|c|}{ Yes } \\
\hline $\mathrm{R}^{2}$ & \multicolumn{2}{|c|}{$\begin{array}{c}0.930 \\
109557\end{array}$} & \multirow{2}{*}{\multicolumn{2}{|c|}{0.989}} & & \\
\hline $\mathrm{F}$ & \multirow{2}{*}{\multicolumn{2}{|c|}{$\begin{array}{c}10955.7 \\
208\end{array}$}} & & & & \\
\hline $\mathrm{N}$ & & & \multicolumn{2}{|c|}{208} & \multicolumn{2}{|c|}{208} \\
\hline
\end{tabular}

Clustered standard errors by country in parentheses.

${ }^{*} p<0.1,{ }^{* *} p<0.05,{ }^{* * *} p<0.01$

Note: Transport emissions, population, real per capita GDP, transport energy intensity and transport volume are taken in natural logarithms.

For the transport mode share, the shift from road to rail is the only one that would cut transport emissions in both regions, as the estimated parameters, with a coefficient of -2.851 for the western EU region and -0.444 for the eastern EU region, have the expected negative sign and are statistically significant. Likewise, the reduction in emissions would be greater in the western countries as a consequence of this switch. With regard to waterborne transport, the reduction in transport emissions by shifting from road to waterborne transport would only be effective in the western region, where the negative estimated coefficient, -0.761 , is statistically significant at a significance level of $1 \%$. According to this regional analysis, the replacement of road with rail or waterborne transport would have a greater impact on emission reduction in the western region. Finally, concerning aviation, the positive coefficient estimated is statistically significant in the eastern region; thus, a larger share of aviation at the expense of road transport would mean higher transport emissions in this region. As mentioned in the previous section, aviation only covers domestic aviation activity. If aviation included international activity, the result is very likely to be statistically significant in the western region too.

Regarding the mix of energy sources, shifting from oil products towards renewable energies or gas would improve the transport emissions in both regions, as their estimated coefficients are negative and statistically significant. However, the effect of switching from oil products to 
renewable energies on reducing transport emissions is apparently greater in the eastern region, with a coefficient of -1.500 , while the effect of a shift towards gas is greater in the western region, with a coefficient of -1.278 . In relation to electricity, the analysis of the EU transport activity as a whole did not provide a conclusive result. However, we are now in a position to give a response. The replacement of oil products with electricity would decrease the emissions in the western region, given that its estimated parameter, -2.646 , is negative and statistically significant, while it seems that it would not have any impact in the eastern region, given that its coefficient is not statistically significant at any significance level. The result for the western region is as expected, as the use of electricity as a source of energy is less polluting than the use of oil products. In the next section, we provide an explanation for this result for the eastern region in relation to electricity.

\subsection{DISCUSSION AND POLICY IMPLICATIONS}

The above results indicate that population, economic activity, transport volume, transport energy intensity, modal share and energy mix are driving factors of transport emissions in the EU in the period 1990-2014. In particular, population followed by transport energy intensity are more meaningful in explaining transport emissions than economic activity and/or transport volume. This outcome somewhat differs from the previous empirical evidence for other regions and periods, given that in most investigations economic activity is the main driving factor of transport emissions followed by population or, alternatively, by transport energy intensity (Lakshmanan and Han, 1997; Mazzarino, 2000; Timilsina and Shrestha, 2009; Guo et al., 2014; M'raihi et al., 2015; Fan and Lei, 2016; Xu and Lin, ${ }^{13}$ 2015, 2016). In some other cases, transport volume turns to be the main driving factor (Scholl et al., 1996; Kwon, 2005; Steinhoff et al., 2006). The result of the great importance of transport energy intensity as a driving factor of the EU transport emissions, especially in the eastern region, is very relevant. It shows that improvements in energy intensity can contribute to alleviating the transport emissions' growth considerably. In other words, environmental policies focused on driving energy efficiency in transport activity, for instance replacing old vehicles with other technologically more energy-efficient ones, the use of higher-quality fuels and infrastructure improvements, would have a greater impact on reducing the transport emissions in the EU, with a higher transport energy intensity elasticity, than in other world regions, for example China (Zhang and Nian, 2013; Xu and Lin, 2015, 2016). Moreover, it is worth mentioning that the positive effect on the EU transport emissions derived from improvements in energy

\footnotetext{
${ }^{13}$ In the study by $\mathrm{Xu}$ and Lin $(2015,2016)$, urbanization level and private car ownership are substituted for population.
} 
efficiency would be limited or even insufficient if they were accompanied by significant increases in population, economic activity and/or transport volume.

Another finding of our work is that the EU transport emissions show relative decoupling in relation to transport activity in particular and economic activity in general. Relative decoupling means that the growth rate of transport emissions is lower than the growth rate of transport (or economic) activity; then, the environmental impact per unit of transport activity (or economic output) drops (UNEP, 2011)—though the transport emissions could be rising in absolute terms. Likewise, the phenomenon of relative decoupling occurs in both regions. However, when it is related to economic activity, the decoupling is greater in the eastern region, while, when related to transport activity, it is greater in the western region. Various previous works also find relative decoupling among transport emissions, economic activity and transport volume, such as those on China by Zhang and Nian (2013) and Xu and Lin (2016). In these relative decoupling is much less important regarding the Chinese economic activity, but, in relation to transport volume, our work is in the same vein as the results for China of Xu and Lin (2016), while the work for China of Zang and Nian (2015) shows a higher relative level of decoupling.

Another outstanding result of the analysis is related to the modal share and energy source mix. Previous literature, for instance the works of Scholl et al. (1996) on nine OCDE countries, Lakshmanan and Han (1997) on the USA and Steenhof et al. (2006) on Canada, find that the modal share is a significant driving factor of transport emissions, but, on the contrary, the investigation of Timilsina and Shrestha (2009) into selected Asian countries points out that the modal share is a minor driving factor. As regards the energy mix, the previously mentioned works of Steenhof et al. (2006) and Timilsina and Shrestha (2009), and the studies on China by Guo et al. (2014) and on Beijing by Fan and Lei (2016), determine that the energy mix is a minor driving factor of transport emissions. Nevertheless, the aforementioned literature analyzes the importance of the modal share and/or of the energy mix as a whole. By contrast, our investigation takes a step further by studying the modal share in detail through quantifying the impact on transport emissions resulting from the substitution of rail or waterborne or aviation for road transport and by analyzing the energy source mix in detail through quantifying the impact on transport emissions resulting from the substitution of electricity or renewable energies or gas for oil products. That is, our analysis allows us to determine the contribution to transport emissions of a change in modal share and of a change in energy mix. We conclude that both the modal share and the energy mix are driving factors of the EU transport emissions during the period analyzed.

In particular, in relation to the modal share, we find that the preferred alternative mode of transport to road is rail, given that, when substituting road with the other alternative modes of 
transport-rail, waterborne or aviation-rail would lead to a larger decline in transport emissions. However, the intensity of diminishing transport emissions due to this substitution would depend on the energy source mix used in the modes of transport involved. For instance, the analysis by regions shows that the impact on diminishing transport emissions as a result of shifting from road to rail is greater in the western EU region. This is because electricity accounts for $69.3 \%$ of the total rail energy consumption in the western region in 2014, while in the eastern region electricity only achieves $54.1 \%$; that is, the use of oil products as a source of energy in rail is lower in the western region (30.0\%) than in the eastern region (45.4\%) (see Tables $A 1$ and $A 2$ in the Appendix); hence, the impact on transport emissions from substituting rail for road would be larger in the EU western region.

Regarding the energy source mix, we find that, among the alternative sources of energyelectricity, renewable energies or gas-from an environmental point of view, the preferred sources of energy to substitute oil products are electricity and renewable energies, due to their greater contribution to diminishing the EU transport emissions. However, despite the positive impact on transport emissions derived from substituting electricity for oil products, the analysis by regions detects a significant reduction in electricity consumption in the eastern region in a period of increasing use of energy on transport activity, which, in turn, produces an unexpected outcome; that is, electricity appears not to be a major driving factor of transport emissions in the eastern region. Nevertheless, there is an explanation for the outcome of non-significance for electricity in that region. During the period 1990-2014, energy use on transport activity increased in the eastern region by $67.3 \%$. Moreover, this growth was accompanied by a change in the energy source mix, increasing the consumption of all sources of energy with the exception of electricity, which decreased. As a result of these changes, the share in the total energy consumption of oil products and electricity decreased, while it increased for renewable energies and gas. That is, renewable energies and gas "substituted" for electricity consumption and, as a consequence, the impact of electricity on transport emissions was "negligible" in the eastern region during the period analyzed (see Table A2 in the Appendix).

The reason for the decrease in electricity consumption in the eastern region is related to the use of rail as a mode of transport. Rail is the main mode of transport that uses electricity as a source of energy. Thus, in 2014 rail's electricity consumption amounted to $88.8 \%$ of the total electricity consumption in transport activity in the eastern region. During 1990-2014 rail's energy consumption in this region decreased by $44.9 \%$, which resulted in a reduction of electricity consumption by $25.8 \%$. This decline in rail's energy consumption, and hence the reduction of electricity use, was a consequence of rail's activity contraction during the period analyzed. The study by Pucher and Buehler (2005) makes reference to a transport revolution 
since the extinction of Communism in the late 1980s in these countries. It points out the extraordinary growth of private car ownership and use and the associated downturn in public transport use; in addition, this pattern in passenger transport is accompanied by a shift in freight transport from rail to truck. Thus, rail activity loses significance in favor of road transport, cutting the consumption of electricity in transport activity in the eastern region. At the same time, this substitution of road for rail means, in fact, a shift from electricity to oil products, which explains the higher transport energy intensity level and its significance as a driving factor in the eastern region; indeed, the energy intensity of transport activity in the eastern region increased during the period analyzed, whereas it experienced a reduction in the western region. In short, data showed that between 1995 and 2013, transport energy intensity decreased by $7.4 \%$ in western EU, whereas it increased $21.4 \%$ in eastern EU. Therefore, given these results, policies promoting the use of rail, such as investments in rail infrastructures that facilitate multimodality, ${ }^{14}$ or measures fostering the use of electricity, for instance investments in electrifying the rail network or encouraging the use of electric vehicles, will help substantially in curbing EU transport emissions.

Finally, in the 2011 Transport White Paper, some guidance it is provided to achieve the goal of reducing the transport activity emissions by $60 \%$ by 2050 in relation to 1990 . Specifically, the proposals are: i) to eliminate gradually conventionally fueled cars in cities, ii) to substitute rail and waterborne transport for $50 \%$ of road transport, iii) to use $40 \%$ of low-carbon fuels in aviation and, finally, iv) to reduce shipping emissions by at least $40 \%$ (European Commission, 2011). Given the results obtained in this research, it can be said in relation to these proposals that, first, regarding the gradual elimination of conventionally fueled cars in cities, it will effectively decrease EU transport emissions, given that switching from oil products to alternative sources of energy, such as electricity, renewable energies or even gas, leads to a reduction in transport emissions, although electricity should be the preferred source due to its larger impact on the reduction of EU transport emissions. With regard to substituting rail or waterborne transport for $50 \%$ of road transport, it will in effect lessen the EU transport emissions, as the shift from road to rail or waterborne transport cuts transport emissions, but rail should be the favored alternative mode of transport given that its impact on cutting emissions is greater than that of waterborne transport. As regards the promotion of low-carbon fuels in aviation, our empirical analysis shows that an increase in aviation activity at the expense of roads will lead to an increase in the EU transport emissions. ${ }^{15}$ Therefore, the only effective measure to reduce aviation emissions will be precisely to draw on low-

\footnotetext{
${ }^{14}$ Multimodality refers to the integration of all modes of transport by guaranteeing the interoperability of the transport system at all levels.

${ }^{15}$ The corresponding estimated coefficients are positive for the EU as a whole, the western EU and the eastern EU, although they are only statistically significant in the FGLS estimates for the EU as a whole and in the PCSE and FGLS estimates for the eastern EU.
} 
carbon fuels and, when possible, switch to other transport modes, at least until the development of new technologies in the future that allow the use of alternative sources of energy in aviation-new technologies, such as solar energy, have been developed recently, but they still cannot be used commercially. To conclude, in relation to the target of reducing shipping emissions by at least $40 \%$, to achieve this goal, besides a reduction in shipping needs by improving logistics, three other measures could be adopted: i) shifting from oil products to other sources of energy, such as renewable energies, gas or electricity; ii) encouraging the use of sustainable low-carbon fuels; and, finally, iii) improving energy efficiency. We have just seen empirically that these three measures could work.

Nevertheless, some limitations of the previous analysis must be considered. First, this research excludes international bunker emissions (international maritime transport and international aviation emissions) from the analysis due to a lack of data or equivalent data. Taking into account that maritime bunker fuels accounted for $11.5 \%$ of the total EU transport energy consumption in 2012 and that aviation ${ }^{16}$ accounted for 12.4\% (DG MOVE, 2015), and that in 2014 in terms of emissions each one accounted for $11.7 \%$ of transport emissions (EEA, 2017), our results could be misleading. In fact, in the various econometric models estimated, the results for the parameters of aviation and waterborne transport are slightly or not significant. It is likely that the inclusion of these data led to more significant outcomes for aviation and waterborne transport parameters independently of the EU region analyzed and the econometric model used. In this sense the availability of data on the activities of passengers and freight in international aviation and waterborne transport, in equivalent units to those used in other modes of transport, would be particularly relevant to improving the estimation of the impact of these two modes of transport. Second, it is noticeable that the impact of the different renewable energies on transport emissions differs substantially. Let us take biofuels, the most important alternative fuel among renewable energies, as an example. There are three types of biofuels, referred to as first-, second- and third-generation biofuels. The second- and third-generation biofuels are more sustainable than the first-generation biofuels, as they can achieve greater transport emission savings (DG MOVE, 2015). Thus, the renewable energies mix is important in studying their impact on transport emissions. Due to a lack of data, this is a limitation of our work that must be considered. Third, to conclude, it would also be important to include in the previous analysis the interdependencies among countries, especially those cases in which the transport emissions in some countries could be explained, at least partially, by the transport activity in other countries.

\footnotetext{
${ }^{16}$ Domestic aviation accounts for about $11.0 \%$ of the energy consumption of EU aviation (Eurostat, 2016).
} 


\section{CONCLUSIONS}

The greenhouse gas emissions of the EU transport activity increased by $13.3 \%$ in the period 1990-2014 and are currently the second-largest source of emissions after the energy sector. This trend in transport emissions needs to be reversed to satisfy the 2011 Transport White Paper objective, which consists of reducing the activity's emissions by $60 \%$ by 2050 in relation to 1990 (European Commission, 2011).

The objective of this paper is to identify the driving factors of the transport emissions in the EU during the period 1990-2014. With this purpose, we employ an extended STIRPAT model, which allows us to include several driving factors: population, economic activity, transport volume, transport energy intensity and transport activity composition in terms of modal share and of energy source mix. Unlike the previous literature, the introduction into the STIRPAT model of the shares of each mode of transport and of each source of energy allows us to identify the modes of transport and the sources of energy that would contribute more to cutting transport emissions. The use of panel data econometric techniques enables to quantify the impact of each driving factor on transport emissions. Moreover, the analysis is performed considering the EU as a whole as well as by regions, the western EU and the eastern EU, which differ in their geographical position, economic structure and level of development.

We conclude that the population, real per capita GDP, transport volume, transport energy intensity, and changes in modal share and in energy source mix are driving factors of greenhouse gas emissions in the EU transport sector in the period 1990-2014. The outcomes of the analysis by region are similar to the results obtained for the whole EU. Regardless of the region analyzed, the impact on transport emissions of the different drivers are the same qualitatively but not quantitatively. This regional analysis could thus also be interpreted as a robustness test of the findings achieved for the EU as a whole.

In particular, the outcomes show that population and transport energy intensity are more meaningful in explaining EU transport emissions than economic activity and/or transport volume. Specifically, the EU transport emissions show relative decoupling in relation to transport activity in particular and economic activity in general. In the same way, the preferred alternative mode of transport to road is rail, and electricity is the favored alternative source of energy to oil products, since both, changing to rail and changing to electricity, have the most significant impact on reducing the EU transport emissions.

These results are crucial for designing environmental policies focused on successfully reducing emissions in the EU transport activity. They should be aimed especially at promoting energy saving and efficient energy use but also encouraging the shift from road to 
other modes of transport that are more environmentally friendly, such as rail, or substituting the use of oil products as a source of energy with other less polluting sources of energy, such as electricity.

In terms of the environmental actions promoted by the 2011 Transport White Paper to achieve the objective of cutting transport emissions, the above results point out that, among all the targets proposed, the most effective in reducing transport emissions would apparently be improvements in transport energy intensity, the substitution of rail for road transport and, finally, the switch from oil products to electricity. It should be noted that the results obtained here only take into account direct transport emissions; therefore, the effectiveness in diminishing the total-direct and indirect-transport emissions from the substitution of electricity for oil products depends on the source used to obtain this electricity. However, it is worth mentioning that all of the measures proposed in the Transport White Paper would contribute to cutting transport emissions.

\section{ACKNOWLEDGEMENTS}

We thank Josep Lluis Raymond and three anonymous reviewers for their helpful comments. We acknowledge support from project ECO2015-67524-R, from the Spanish Ministry of Economics and Competitiveness and FEDER. 


\section{APPENDIX}

Table A1. Energy consumption by mode of transport and source of energy: western EU region, 1990-2014

\begin{tabular}{|c|c|c|c|c|c|c|c|}
\hline \multicolumn{2}{|l|}{ Western EU } & Oil products & Electricity & Renewable & Gas & Solid fuel & Total \\
\hline \multirow{3}{*}{ Road } & 1990 & 214531.6 & 1.5 & 5.7 & 208.6 & 0 & 214747.4 \\
\hline & 2014 & 232564.9 & 32 & 12225.5 & 1311.7 & 0 & 246134.1 \\
\hline & Variation & & & & & & $14.6 \%$ \\
\hline \multirow{3}{*}{ Rail } & 1990 & 2904.8 & 3230 & 0 & 0 & 19.8 & 6154.6 \\
\hline & 2014 & 1513.9 & 3492.1 & 26.1 & 0 & 7.7 & 5039.8 \\
\hline & Variation & & & & & & $-18.1 \%$ \\
\hline \multirow{3}{*}{ Aviation international } & 1990 & 22197.3 & 0 & 0 & 0 & 0 & 22197.3 \\
\hline & 2014 & 41665.5 & 0 & 0 & 0 & 0 & 41665.5 \\
\hline & Variation & & & & & & $87.7 \%$ \\
\hline \multirow{3}{*}{ Aviation domestic } & 1990 & 5402.1 & 0 & 0 & 0 & 0 & 5402.1 \\
\hline & 2014 & 5214.7 & 0 & 0 & 0 & 0 & 5214.7 \\
\hline & Variation & & & & & & $-3.5 \%$ \\
\hline \multirow{3}{*}{ Waterborne transport } & 1990 & 5801.5 & 0 & 0 & 0 & 0 & 5801.5 \\
\hline & 2014 & 4173 & 0 & 4.7 & 0 & 0 & 4177.7 \\
\hline & Variation & & & & & & $-28.0 \%$ \\
\hline \multirow{3}{*}{ Pipelines } & 1990 & 0 & 52.1 & 0 & 96.7 & 0 & 148.8 \\
\hline & 2014 & 0 & 54 & 0 & 750.2 & 0 & 804.2 \\
\hline & Variation & & & & & & $440.5 \%$ \\
\hline \multirow{3}{*}{ Others } & 1990 & $306.9^{a}$ & 763.8 & 0 & 0 & 0 & 1070.7 \\
\hline & 2014 & 369.2 & 1037.5 & 7.3 & 33.4 & 0 & 1447.4 \\
\hline & Variation & & & & & & $35.2 \%$ \\
\hline \multirow{3}{*}{ Total } & 1990 & 251144.2 & 4047.4 & 5.7 & 305.3 & 19.8 & 255522.4 \\
\hline & 2014 & 285501.2 & 4615.6 & 12263.6 & 2095.3 & 7.7 & 304483.4 \\
\hline & Variation & $13.7 \%$ & $14.0 \%$ & $215050.9 \%$ & $586.3 \%$ & $-61.1 \%$ & $19.2 \%$ \\
\hline
\end{tabular}

Source: Prepared by the authors with data from Eurostat (2016).

Note: ${ }^{a}$ Data for Germany are not available for this year. 
Table A2. Energy consumption by mode of transport and source of energy: eastern EU region, 1990-2014

\begin{tabular}{|c|c|c|c|c|c|c|c|}
\hline Eastern EU & & Oil products & Electricity & Renewable & Gas & Solid fuel & Total \\
\hline \multirow{3}{*}{ Road } & 1990 & 21836.9 & 20.3 & 0 & 7.4 & 0 & 21864.6 \\
\hline & 2014 & 38853.4 & 31.9 & 1785.1 & 136.2 & 0 & 40806.6 \\
\hline & Variation & & & & & & $86.6 \%$ \\
\hline \multirow{3}{*}{ Rail } & 1990 & $1081^{a}$ & 850.5 & 0 & 0 & 188.2 & 2119.7 \\
\hline & 2014 & 530.3 & 631.2 & 4.8 & 0 & 0.9 & 1167.2 \\
\hline & Variation & & & & & & $-44.9 \%$ \\
\hline \multirow{3}{*}{ Aviation international } & 1990 & 1514.6 & 0 & 0 & 0 & 0 & 1514.6 \\
\hline & 2014 & 1833.7 & 0 & 0 & 0 & 0 & 1833.7 \\
\hline & Variation & & & & & & $21.1 \%$ \\
\hline \multirow{3}{*}{ Aviation domestic } & 1990 & 58 & 0 & 0 & 0 & 0 & 58 \\
\hline & 2014 & 91.6 & 0 & 0 & 0 & 0 & 91.6 \\
\hline & Variation & & & & & & $57.9 \%$ \\
\hline \multirow{3}{*}{ Waterborne transport } & 1990 & 580.5 & 0 & 0 & 0 & 5.5 & 586 \\
\hline & 2014 & 111.9 & 0 & 0 & 0 & 0 & 111.9 \\
\hline & Variation & & & & & & $-80.9 \%$ \\
\hline \multirow{3}{*}{ Pipelines } & 1990 & 0 & 20.8 & 0 & 25.9 & 0 & 46.7 \\
\hline & 2014 & 1 & 39.6 & 0 & 715.9 & 0 & 756.5 \\
\hline & Variation & & & & & & $1519.9 \%$ \\
\hline \multirow{3}{*}{ Others } & 1990 & 72.6 & 512.1 & 13.1 & 0 & 0 & 597.8 \\
\hline & 2014 & 39.2 & 8.4 & 1.8 & 8.5 & 0 & 57.9 \\
\hline & Variation & & & & & & $-90.3 \%$ \\
\hline \multirow{3}{*}{ Total } & 1990 & 25143.6 & 1403.7 & 13.1 & 33.3 & 193.7 & 26787.4 \\
\hline & 2014 & 41461.1 & 711.1 & 1791.7 & 860.6 & 0.9 & 44825.4 \\
\hline & Variation & $64.9 \%$ & $-49.3 \%$ & $13577.1 \%$ & $2484.4 \%$ & $-99.5 \%$ & $67.3 \%$ \\
\hline
\end{tabular}

Source: Prepared by the authors with data from Eurostat (2016).

Note: ${ }^{a}$ Data for Romania are not available for this year. 
Table A4. Collinearity diagnostics

\section{EU}

\begin{tabular}{|c|c|c|c|c|}
\hline \multirow[b]{2}{*}{ Variable } & \multicolumn{2}{|c|}{ SQRT } & R- & \multirow[b]{2}{*}{ Squared } \\
\hline & VIF & VIF & Tolerance & \\
\hline $\mathrm{P}$ & 1.70 & 1.30 & 0.5878 & 0.4122 \\
\hline GDP & 4.06 & 2.02 & 0.2463 & 0.7537 \\
\hline EI & 3.62 & 1.90 & 0.2762 & 0.7238 \\
\hline $\mathrm{TA}$ & 2.74 & 1.65 & 0.3652 & 0.6348 \\
\hline RAIL & 3.55 & 1.88 & 0.2819 & 0.7181 \\
\hline AVIA & 1.27 & 1.13 & 0.7894 & 0.2106 \\
\hline NAV & 1.22 & 1.10 & 0.8192 & 0.1808 \\
\hline ELE & 1.89 & 1.37 & 0.5296 & 0.4704 \\
\hline REN & 1.24 & 1.12 & 0.8035 & 0.1965 \\
\hline GAS & 1.21 & 1.10 & 0.8247 & 0.1753 \\
\hline
\end{tabular}

Mean VIF 2.25

\section{Western EU region}

\begin{tabular}{|c|c|c|c|c|}
\hline \multirow[b]{2}{*}{ Variable } & \multicolumn{2}{|c|}{ SQRT } & R- & \multirow[b]{2}{*}{ Squared } \\
\hline & VIF & VIF & Tolerance & \\
\hline $\mathrm{P}$ & 1.89 & 1.37 & 0.5297 & 0.4703 \\
\hline GDP & 2.28 & 1.51 & 0.4395 & 0.5605 \\
\hline EI & 1.91 & 1.38 & 0.5239 & 0.4761 \\
\hline TA & 2.89 & 1.70 & 0.3462 & 0.6538 \\
\hline RAIL & 6.76 & 2.60 & 0.1480 & 0.8520 \\
\hline AVIA & 2.16 & 1.47 & 0.4622 & 0.5378 \\
\hline NAV & 1.74 & 1.32 & 0.5750 & 0.4250 \\
\hline ELE & 6.77 & 2.60 & 0.1478 & 0.8522 \\
\hline REN & 1.48 & 1.22 & 0.6736 & 0.3264 \\
\hline GAS & 2.33 & 1.53 & 0.4298 & 0.5702 \\
\hline
\end{tabular}

Mean VIF 3.02

\section{Eastern EU region}

\begin{tabular}{|c|c|c|c|c|}
\hline \multirow[b]{2}{*}{ Variable } & \multicolumn{2}{|c|}{ SQRT } & R- & \multirow[b]{2}{*}{ Squared } \\
\hline & VIF & VIF & Tolerance & \\
\hline $\mathrm{P}$ & 2.41 & 1.55 & 0.4148 & 0.5852 \\
\hline GDP & 5.67 & 2.38 & 0.1764 & 0.8236 \\
\hline EI & 3.39 & 1.84 & 0.2949 & 0.7051 \\
\hline TA & 7.15 & 2.67 & 0.1398 & 0.8602 \\
\hline RAIL & 3.42 & 1.85 & 0.2925 & 0.7075 \\
\hline AVIA & 1.63 & 1.28 & 0.6119 & 0.3881 \\
\hline NAV & 1.54 & 1.24 & 0.6483 & 0.3517 \\
\hline ELE & 2.76 & 1.66 & 0.3627 & 0.6373 \\
\hline REN & 1.91 & 1.38 & 0.5231 & 0.4769 \\
\hline GAS & 1.47 & 1.21 & 0.6811 & 0.3189 \\
\hline
\end{tabular}

Mean VIF 3.14 


\section{REFERENCES}

Andreoni, V. and Galmarini, S. (2012) European $\mathrm{CO}_{2}$ emissions trends: A decomposition analysis for water and aviation transport sectors. Energy, vol. 45, 1, pp. 595-602.

Banister, D. and Hickman, R. (2013) Transport futures: Thinking the unthinkable. Transport Policy, vol. 29, pp. 283-293.

DG MOVE (Directorate General for Mobility and Transport) (2015) State of the art on alternative fuels transport systems in the European Union. Final Report. Expert Group on Future Transport Fuels. European Commission, Brussels.

Dietz, T. and Rosa, E. A. (1994) Rethinking the environmental impacts of population, affluence and technology. Human Ecology Review, vol. 1, 2, pp. 277-300.

Dietz, T. and Rosa, E. A. (1997) Effects of population and affluence on $\mathrm{CO}_{2}$ emissions. PNAS, Proceedings of the National Academy of Sciences, vol. 94, 1, pp. 175-179.

EEA (2017) Greenhouse gas emissions from transport. Retrieved: July 13, 2017 https://www.eea.europa.eu/data-and-maps/indicators/transport-emissions-of-greenhousegases/transport-emissions-of-greenhouse-gases-10

Ehlrich, P. and Holdren, J. (1971) Impact of population growth. Science, 171, pp. 1212-1217.

Ehlrich, P. and Holdren, J. (1972) A bulletin dialogue on the 'Closing Circle'. Critique: one dimensional ecology. Bulletin of the Atomic Scientists, vol. 28, 5, pp. 16-27.

Eliasson, J. and Proost, S. (2015) Is sustainable transport policy sustainable? Transport Policy, vol. 37, pp. 92-100.

Enerdata (2016) Odyssee-Mure. Odyssee database. Retrieved: July 29, 2016 http://www.indicators.odyssee-mure.eu/energy-efficiency-database.html

European Commission (2011) White paper. Roadmap to a Single European Transport Area - Towards a competitive and resource efficient transport system. COM/2011/0144 final. http://ec.europa.eu/transport/themes/strategies/2011 white paper en.htm

European Commission (2013) Analysis of greenhouse gas emission trends and drivers. Publications Office of the European Union, Luxembourg. http://publications.jrc.ec.europa.eu/repository/bitstream/JRC78707/lb-na-25814-en-n.pdf and http://edgar.jrc.ec.europa.eu/docs/AETAD binder 201307253 with template.pdf 
Eurostat (2016) Emissions of greenhouse gases and air pollutants, population, and energy statistics - Quantities, annual data. Office for Official Publications of the European Communities, Luxemburg. Retrieved: July 29, 2016 http://epp.eurostat.ec.europa.eu

Fan, F. and Lei, Y. (2016) Decomposition analysis of energy-related carbon emissions from the transportation sector in Beijing. Transportation Research Part D: Transport and Environment, vol. 42, pp. 135-145.

Grazi, F. and van den Bergh, J. C. J. M. (2008) Spatial organization, transport, and climate change: Comparing instruments of spatial planning and policy. Ecological Economics, vol. 67 , pp. 630-639.

Greening, L. A., Greene, D. L. and Difiglio, C. (2000) Energy efficiency and consumption the rebound effect - a survey. Energy Policy, vol. 28, pp. 389-401.

Guo, B., Geng, Y., Franke, B., Hao, H., Liu, Y. and Chiu, A. (2014) Uncovering China's transport $\mathrm{CO}_{2}$ emission patterns at the regional level. Energy Policy, vol. 74, pp. 134-146.

Kahn Ribeiro, S., S. Kobayashi, M. Beuthe, J. Gasca, D. Greene, D. S. Lee, Y. Muromachi, P. J. Newton, S. Plotkin, D. Sperling, R. Wit, P. J. Zhou, 2007: Transport and its infrastructure. In Climate Change 2007: Mitigation. Contribution of Working Group III to the Fourth Assessment Report of the Intergovernmental Panel on Climate Change [B. Metz, O.R. Davidson, P.R. Bosch, R. Dave, L.A. Meyer (eds.)], Cambridge University Press, Cambridge, United Kingdom and New York, NY, USA.

Hickman, R. and Banister, D. (2007) Looking over the horizon: Transport and reduced $\mathrm{CO}_{2}$ emissions in the UK by 2030. Transport Policy, vol. 14, pp. 377-387.

Hickman, R., Ashiru, O. and Banister, D. (2010) Transport and climate change: Simulating the options for carbon reduction in London. Transport Policy, vol. 17, pp. 110-125.

Hoechle, D. (2007) Robust standard errors for panel regressions with cross-sectional dependence. Stata Journal, vol. 7, pp. 281-312.

Hull, A. (2008) Policy integration: What will it take to achieve more sustainable transport solutions in cities? Transport Policy, vol. 15, pp. 94-103.

Hsiao, C. (1986) Analysis of Panel Data. Cambridge University Press, Cambridge.

International Energy Agency (IEA) (1997) Indicators of Energy Use and Efficiency. Understanding the Link between Energy and Human Activity. OECD/IEA, Paris. 
Kaya, Y. (1989) Impact of carbon dioxide emission control on GNP growth: Interpretation of proposed scenarios. Paper presented to the Energy and Industry Subgroup, Response Strategies Working Group, Intergovernmental Panel on Climate Change, Paris.

Kwon, T.-H. (2005) Decomposition factors determining the trend of $\mathrm{CO}_{2}$ emissions from car travel in Great Britain (1970-2000). Ecological Economics, vol. 53, pp. 261-275.

Lakshmanan, T. R. and Han, X. (1997) Factors underlying transportation $\mathrm{CO}_{2}$ emissions in the USA: A decomposition analysis. Transportation Research Part D, vol. 2, pp. 1-15.

Marrero, G. A. (2010) Greenhouse gases emissions, growth and the energy mix in Europe. Energy Economics, vol. 32, pp. 1356-1363.

Mazzarino, M. (2000) The economics of the greenhouse effect: evaluating the climate change impact due to the transport sector in Italy. Energy Policy, vol. 28, pp. 957-966.

M'raihi, R., Mraihi, T., Harizi, R. and Bouzidi, M. T. (2015) Carbon emissions growth and road freight: Analysis of the influencing factors in Tunisia. Transport Policy, vol. 42, pp. 121129.

Papagiannaki, K. and Diakoulaki, D. (2009) Decomposition analysis of CO2 emissions from passenger cars: The cases of Greece and Denmark. Energy Policy, vol. 37, pp. 32593267.

Pucher, J. and Buehler, R. (2005) Transport policy in post-communist Europe. In Button, K. J. and Hensher, D. A. (Eds), Handbook of Transport Strategy, Policy and Institutions. Handbooks in Transport, volume 6. Elsevier, Amsterdam, pp. 725-744.

Shaffer, M.E. and Stillman, S. (2010) xtoverid: Stata module to calculate tests of overidentifying restrictions after xtreg, xtivreg, xtivreg2 and xthtaylor http://ideas.repec.org/c/boc/bocode/s456779.html

Scholl, L., Schipper, L. J. and Kiang, N. (1996) $\mathrm{CO}_{2}$ emissions from passenger transport: A comparison of international trends from 1973 to 1992. Energy Policy, vol. 24, 1, pp. 1730 .

Sobrino, N. and Monzon, A. (2014) The impact of the economic crisis and policy actions on GHG emissions from road transport in Spain. Energy Policy, vol. 74, pp. 486-498. 
Steenhof, P., Woudsma, C. and Sparling, E. (2006) Greenhouse gas emissions and the surface transport of freight in Canada. Transportation Research Part D, vol. 11, pp. 369376.

Stern, D. I. (2004) The rise and fall of the Environmental Kuznets Curve. World Development, vol. 32, 8, pp. 1419-1439.

Tang, T-Q., Huang, H-J. and Shang, H-Y. (2015) Influences of the driver's bounded rationality on micro driving behavior, fuel consumption and emissions. Transportation Research Part D, vol. 41, pp. 423-432.

Tang, T-Q., Yi, Z-Y. and Lin, Q-F. (2017) Effects of signal light on the fuel consumption and emissions under car-following model. Physica A, vol. 469, pp. 200-205.

Tight, M.R., Bristow, A.L., Pridmore, A. and May, A.D. (2005) What is a sustainable level of $\mathrm{CO}_{2}$ emissions from transport activity in the UK in 2050? Transport Policy, vol. 12, pp. 235-244.

Timilsina, G. R. and Shrestha, A. (2009) Transport sector $\mathrm{CO}_{2}$ emissions growth in Asia: Underlying factors and policy options. Energy Policy, vol. 37, pp. 4523-4539.

UNEP (2011) Decoupling natural resource use and environmental impacts from economic growth. A report of the Working Group on Decoupling to the International Resource Panel. Fisher-Kowalski, M., Swilling, M., von Weizsäcker, E. U., Ren, Y., Moriguchi, Y., Crane, W., Krausmann, F., Eisenmenger, N., Giljum, S., Hennicke, P., Romero Lankao, P. and Siriban Mananlang, A. United Nations Environment Programme.

World Bank (2016). World Development Indicators: GDP per capita [Data file]. http://data.worldbank.org/indicator/NY.GDP.PCAP.KD

Xu, B. and Lin, B. (2015) Carbon dioxide emissions reduction in China's transport sector: A dynamic VAR (vector autoregression) approach. Energy, vol. 83, pp. 486-495.

Xu, B. and Lin, B. (2016) Differences in regional emissions in China's transport sector: Determinants and reduction strategies. Energy, vol. 95, pp. 459-470.

York, R., Rosa, E. A. and Dietz, T. (2003) STIRPAT, IPAT and ImPACT: analytic tools for unpacking the driving forces of environmental impacts. Ecological Economics, vol. 46, pp. 351-365. 
Yu, L. (1998) Remote Vehicle Exhaust Emission Sensing for Traffic Simulation and Optimization Models. Journal of Transportation Research Part D: Transport and Environment, Vol 3, pp. 337-347.

Zhang, C. and Nian, J. (2013) Panel estimation for transport $\mathrm{CO}_{2}$ emissions and its affecting factors: A regional analysis in China. Energy Policy, vol. 63, pp. 918-926.

Zhu, W-X. (2013) Analysis of $\mathrm{CO}_{2}$ emission in traffic flow and numerical tests. Physica A, vol. 392, pp. 4787-4792. 